\title{
Forming the Strategy for Live Streaming e-Commerce: An Action Research
}

\author{
Cheng-Chieh Wu \\ Industrial Technology Research Institute \\ jangjaycc@gmail.com
}

\author{
Chao-Jung Chen \\ HanChu Co., Ltd. \\ Jeff111869@gmail.com
}

\author{
Tai-Wai Chiang \\ Ant Interaction Tech Co., Ltd. \\ taiwei@antnex.com.tw
}

\begin{abstract}
With the emergence of social media, live streaming change the way of conducting e-business. We focus on investigating the relationship between live-streaming format and its impacts on viewing behavior. Through a participatory action research, this study based on AISAS model to develop the live streaming effectiveness framework. Within two-stage process, research team determined the indicators and real data (i.e., 128 live streams data in 30 days) was collected to examine the performance. The findings confirms celebrity effects and found the existence of lurker situation. The paradox of program design and the cost and benefits is also discussed. Our findings can provide practical suggestions and shed lights for further research on live streaming e-Commerce.
\end{abstract}

\section{Introduction}

The proliferation of mobile and intelligent technologies enables the change for nowadays business. In 2015, Facebook rolled out a new feature that allows power users to broadcast live video stream. Then, it opened to normal users in 2016. According to MarketResearch [15], the global B2C live streaming video platform market size is 12 billion US dollar in 2018, and it is expected to reach 48 billion US dollar by the end of 2025 , with a CAGR of $21.61 \%$. As to the coming of "we media" era, people now can easily share their stories or news through the social media.

As for individuals, live streaming has used for various purposes, including knowledge sharing, experience sharing, entertaining performance, and selling products [14]. Companies also try to leverage the web 2.0 as new means for communicating with consumers and further to enlarge transaction channels. In recent years, the social interaction on social media has attracted many researches. For example, researchers focus on issues including shared content and technical platform [7, 10], building self-brand over cyberspace [16], live streaming usage [14, 20], and the effects of celebrity endorsements on online shopping behavior $[4,12,21]$. Our interest was the relationship between live-streaming format and its impacts of viewing behavior, specifically under the circumstance of live-streaming e-Commerce.

To address our research question, we join with the management team of a live streaming e-commerce company to develop a research relationship using participatory action research (PAR). Before the project, the company owner, one of the authors, had been searching for evaluating the effectiveness of live streaming performance. The company provided an excellent opportunity to investigate our research question. By applying the AISAS (i.e., attention, interest, search, action, and sharing) model, the findings provide suggestions for further improvement to the live streaming program planning of the company.

The rest of the paper is organized as follows. In the next section, we briefly describe the background of live streaming and the development of new eCommerce model. In addition, we review the theoretical base that is the AISAS model. In the research approach section, we describe the research method and research site. In the subsequent section, we present our research results. Then, we discuss the research and managerial implications of our findings and offer suggestions for future research.

\section{Research Background 2.1 Live streaming e-Commerce}

Consumer behavior has been tremendously changed by the emergence of social media. The shared content can be revealed in different format, including text or video, pre-produced or real-time. Past researches has studied the influenced of Web 2.0 on social commerce $[4,6,12,21]$. Tang et al. [19] advocates three-dimensional perspectives for the discussion about live streaming, including synchronous vs symmetric interaction, asynchronous video viewing, and specialized streaming service. $\mathrm{Li}$ 
[13] indicates five types of value (i.e., content, technology, social, emotional, and symbolic) that Internet celebrities can exert their influence. Firms and markers begin to leverage these new means for communicate with their customers for increasing business benefits.

Live streaming brings new possibilities for business world. Unlike traditional TV or online shopping, live streaming e-Commerce reveals a novel consumer buying experience. Through the introduction of host, viewers can interact with the host by asking product-related questions or showing different perspectives of the product. Lu et al. [14] advocated that four elements would influence the engagement with a live streaming, which is host personality and skills, atmosphere, novelty, and authenticity. Du et al. [7] suggested that content value, technology value, and social value would contribute to the success in Web 2.0. Content value refers to the type of information, posting volume, and the presentation. As to technology value, it refers to the usability and sociability of platform. For social value, it represents the host affiliation that is known as fan effects. In general, we regard that the celebrity can bring his or her influence from offline to online. However, when it goes to conducting live streaming e-Commerce, the influence would be questionable.

In this study, we define that the live streaming eCommerce is a host broadcast a live stream for promoting or selling. According to the investigation of Econsultancy [8], about $80 \%$ of social commerce in Asia is conducted over social media like Facebook or Instagram. Following the argument of $\mathrm{Du}$ et al. (2016), we examine the effects of content value and social value on live streaming e-Commerce.

\subsection{AISAS model}

Consumers buying decision is described as a general sequential process, which is the process of attention, interest, desire, memory, and action (i.e., the AIDMA model) [9]. Since the emergence of social media, the information transferred easily anytime and anywhere by using personal computer, mobile phone, or other smart device. In 2004, Dentsu advocated a new consumer behavior model called AISAS (attention, interest, search, action, and share) which is a non linear model [18]. The AISAS model was applied to research different issues. For instance, the AISAS model was used to discuss the effects of social media [1], to explain the consumer behavior patterns $[3,10]$, and to explain the social phenomenon [22]

In this study, we applied AISAS model as the theoretical based for analyzing the live streaming e-
Commerce. By conducting this study, we observe which type of live stream can increase the attention and further become interested. With the real data collected, we would analyze the following viewing behavior, including search, action, and share.

\section{Research Approach}

To address the congruence of both research and practice goals, it led the research team to choose action research (AR) as the research method for the following reasons. First, the company believed that it was necessary that the expertise of authors can contribute to the practice problem. Second, the authors believed that action should be taken to answer the research questions. Third, AR can be possible to satisfy both practical and theoretical interests.

\subsection{Participatory action research}

The basic assumption of AR is that a certain social phenomenon can be studied by introducing change and observing following effects (Baskerville 2001). The essence of $A R$ is proactive in that researchers intervene rather than study a phenomenon after the fact [5]. It links theory and practice in a cyclic process [11].

In this study, we adopted participatory action research as it allows researchers to involve with the organization and to engage the practitioners directly with research questions [17]. This study was conducted based on the AR criteria advocated by Cole et al. [5] as follows:

- Researcher-client agreement: this research project was conducted with the active involvement in a live streaming e-commerce company that committed resources for research.

- Cyclical process model: a four-step research process was developed, including diagnosing, action taking, evaluating and learning.

- The principle of theory: in this research, we apply the AISAS as our theoretical foundation.

- Change through action: with the management support, the suggestions by the research team becomes real actions for further improvement in the company.

- Learning through reflection: researchers provided the observation and the analysis results to the company and were invited for future strategy planning. 


\begin{tabular}{|c|c|c|}
\hline & Stage 1: Baseline Analysis & Stage 2: Viewing Behavior Analysis \\
\hline Period & 2019/10 2019/11 & $2019 / 12^{\sim 2020 / 1}$ \\
\hline Diagnosing & $\begin{array}{l}\text { - Confirm target research problem } \\
\text { - Understand concurrent live } \\
\text { streaming process }\end{array}$ & $\begin{array}{l}\text { - Modified SOPs for preparing } \\
\text { - Confirm action plan for further live } \\
\text { streaming }\end{array}$ \\
\hline Action Taking & $\begin{array}{l}\text { - Participate managerial meeting } \\
\text { - Interview with functional key-men } \\
\text { - Study related literature }\end{array}$ & $\begin{array}{l}\text { - Conducting various forms of live } \\
\text { streaming } \\
\text { - Collect data and analysis viewing } \\
\text { behavior }\end{array}$ \\
\hline Evaluating & $\begin{array}{l}\text { - Shared goal of practical and research } \\
\text { problem } \\
\text { - Utilize AISAS model to explain } \\
\text { situation }\end{array}$ & $\begin{array}{l}\text { - Difference in behavior was found } \\
\text { - The relationships among viewing } \\
\text { behavior factors has been tested }\end{array}$ \\
\hline Learning & $\begin{array}{l}\text { - Figure out improvement for } \\
\text { further live streaming } \\
\text { - Suggest the possible factors for } \\
\text { different viewing behavior }\end{array}$ & $\begin{array}{l}\text { - Results show new possibility for } \\
\text { further improvement } \\
\text { - Suggestions for future strategy }\end{array}$ \\
\hline
\end{tabular}

Figure 1. Research framework and action research cycles

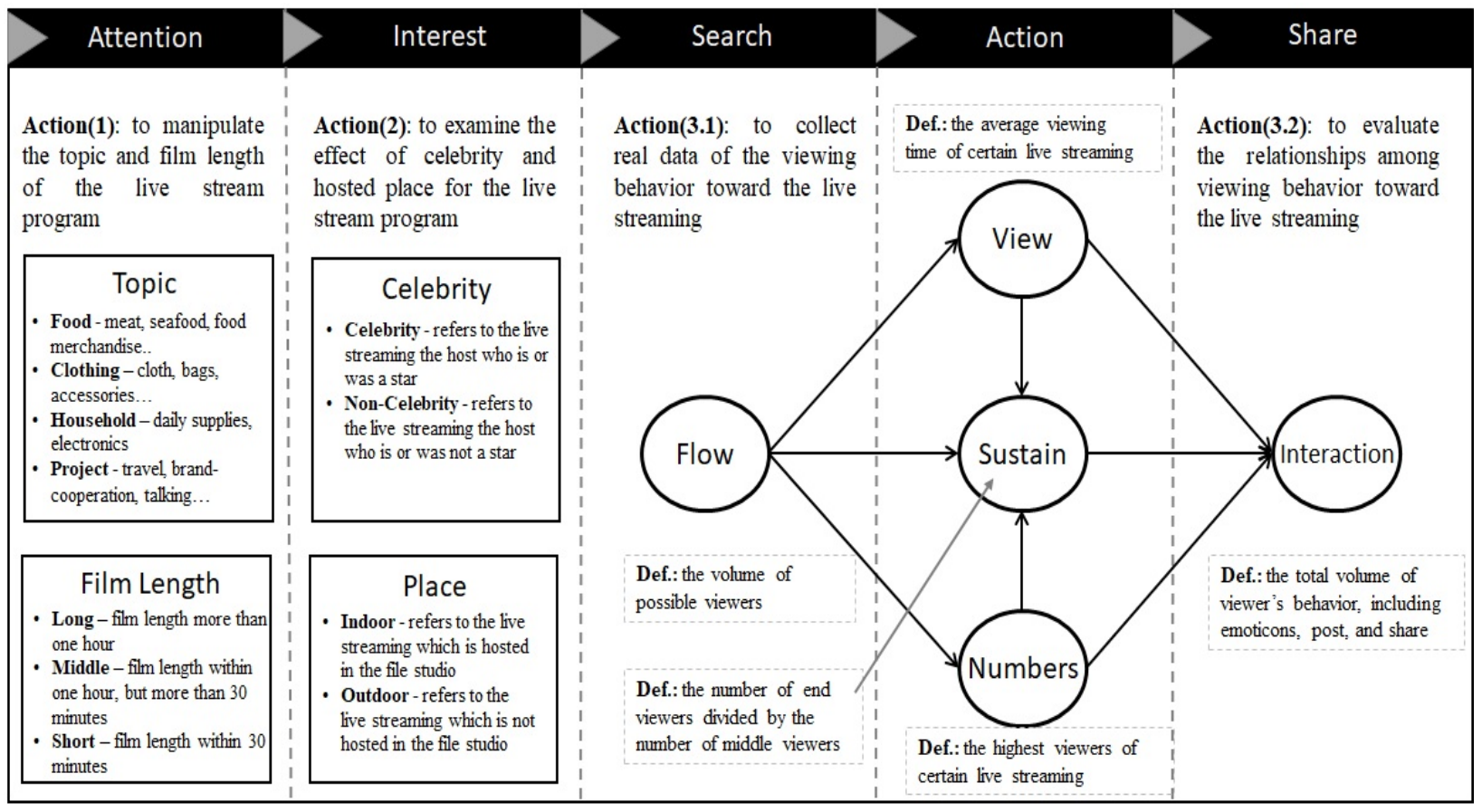

Figure 2. Modified AISAS research model 


\subsection{Research site and research design}

The owner (Aaron, who is also one of the authors) founded HC in 2004 as a mercantile company (all names are pseudonyms). Aaron built live streaming studio for integrating with the e-commerce business of $\mathrm{HC}$ in 2017. With the experience of acting and producing $\mathrm{TV}$ programs, HC leverage the live streaming feature of Facebook and establish its own Facebook fan club, which accumulate 143,994 followers. According to the sales report, HC can sale five tons of mackerel in one day and totally 3,800 tons in 2018. HC keeps innovating in live streaming e-commerce by conducting co-brand program, broadcasting abroad (e.g., Korea, Japan), even trying various product or service (e.g., real estate, travel programs). HC now has twelve live streamers and cooperates with more than 500 suppliers. These enable $\mathrm{HC}$ to be the representative of live streaming e-commerce company in Taiwan.

After two meetings in early October 2019, Aaron invited the other authors to initiate a research proposal for assessing the effectiveness of live streaming. In addition to participate managerial meetings, researchers were authorized to assess the Facebook reports of $\mathrm{HC}$ live streaming. With the clear objectives, the two rounds research proposal was developed soon. In stage 1, we focus on performing intensive requirements analysis to develop an outline for next stage. After baseline analysis, some trial actions were taken and researchers collected related real viewing behavior for further statistical analysis. The overall research framework and AR cycles is shown as Figure 1.

\section{Research Results}

For each of the two action research stages, we present the analysis and discuss the results. The research stages occurred sequentially and the boundaries as shown in Figure 1. The problem resolution and theory development actions often occurred concurrently. The authors turned back to company with the documentation and analysis of each stage before moving on.

\subsection{Stage 1: Baseline Analysis}

After two meetings in early October 2020, the primary research purpose was confirmed by both research and manage team. To better address the assessment of live streaming effectiveness, the researchers firstly conducted several interviews with different functional managers, including purchase, information system, and program producing. As Aaron is the owner of the company, he also provide needed information for research team about the vision and goal of company. The research team chose one of the company's Facebook fan club as research target. On average, this fan club broadcasts 3 to 5 live streaming for promoting product or service package. In order to understand current operating process, we are authorized to assess the flow reports which provide by Facebook.

The draft for describing current live streaming process was developed by using AISAS model. Then, a modified research framework was confirmed after two rounds of revision based on feedback during project team meetings, as shown in Figure 2. The research team proposed three possible assessment actions for the next research round. Firstly, in order to test possible program design for increasing viewers' attention, management team decide to manipulate topic and film length of the following live stream program. Although live streaming provides more cost effective production process in contrast to traditional of TV program, the essence of live streaming is a show which needs incentives for attracting viewers. HC management team had conducted different live streaming content design for stimulating their potential buyers. The research team provided a systematic method by collecting data and further examining the possible effect of content value.

Secondly, company created different program components by inviting celebrity as host and by broadcasting outdoor. According to the AISAS model, we consider that the attention phase puts more emphasis on "what" in a certain live streaming. As to the interest phase, we focus on "how" a live streaming being conducted. In this way, we planned to examine the effects of celebrity and hosted place.

Thirdly, with the congruency between research and practice team, the five viewing behavior indicators were decided, including flow, view, sustain, numbers, and interaction. The research team planned to collect the viewing behavior data in the following 30 days. The five indicators were recorded by the live streaming platform (i.e., Facebook). The research data were collected from the Facebook report. Flow refers to the total volume of possible viewers. The higher value of flow means the wider spread of a certain live stream. The view, sustain, and numbers are the indicators for assessing the action of viewers. View is the average viewing time of certain live streaming. As to numbers, it refers to the highest viewers of certain live stream. Sustain is the number 


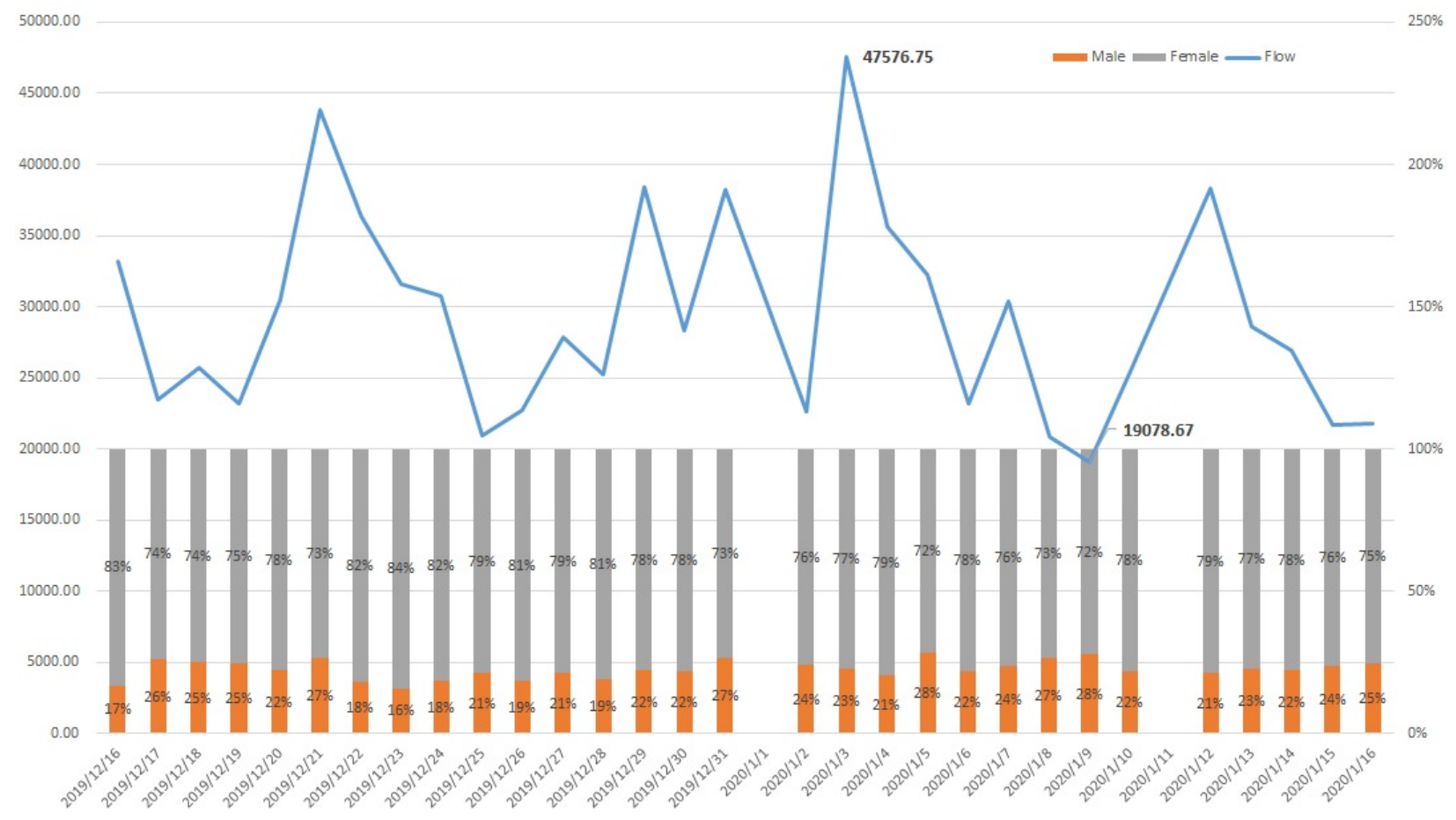

Figure 3. Trends on viewing flow and gender

Table 1. Profiles of live stream evaluation

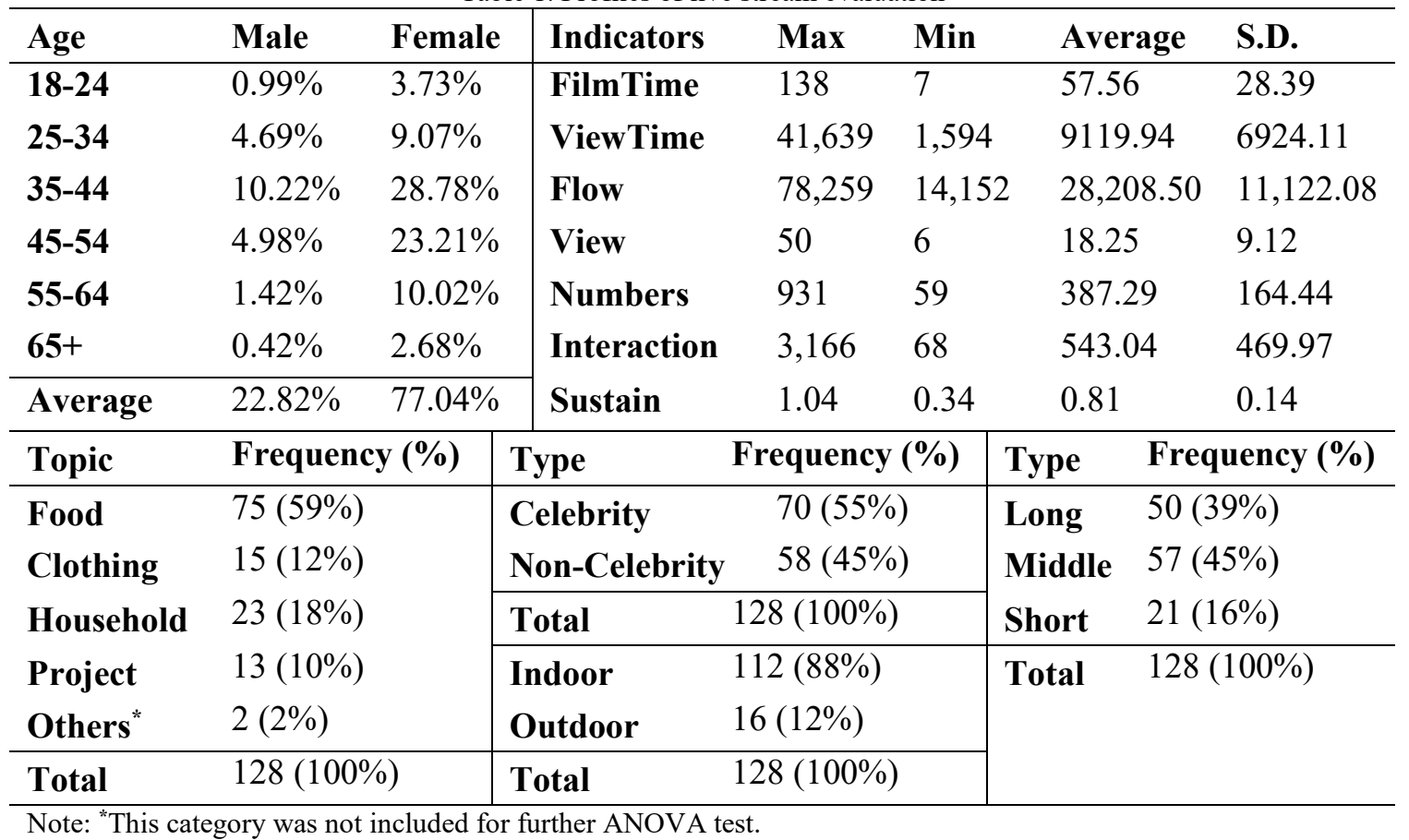


of end viewers divided by the number of middle viewers. The interaction refers to the total volume of view's behavior, including emotions, post, and share.

\subsection{Stage 2: Viewing Behavior Analysis}

The 30 days of live streaming data was collected and analysed in this stage. In the 30 days, there are 128 live streams broadcasted. The trends of viewing flow and gender are shown in Figure 3. Female ( $77.04 \%)$ and the age from 35 to $44(28.78 \%)$ is the main viewing group.

On average, the viewing flow is about 28,209 and live streaming can attract 387 people online viewing at the same time. The highest interaction can be 3,166 and overall the host can retain around $80 \%$ of viewers. The length of live streams can be categorized into long (more than 60 minutes), middle (about 30 to 60 minutes), and short (under 30 minutes). The length of most live streaming is about 30 to 60 minutes. During 30 days, the company broadcast 16 outdoor live streams. Within 128 live streams, there were 70 streams hosted by celebrity. The overall profiles of the 30 days live streams are presented in Table 1.

To evaluate live streaming efficiency, we further conducted several ANOVA tests to test the effects of topic, film length, celebrity, and host place. We found that topic does have influence on view $(\mathrm{F}=$ 2.72, p-value $<0.05)$ and interaction $(\mathrm{F}=2.59$, $\mathrm{p}$ value $<0.10$ ). Our results show significant effect of film length on flow $(\mathrm{F}=13.43$, $\mathrm{p}$-value $<0.001)$, view $(\mathrm{F}=35.96, \mathrm{p}$-value $<0.001)$, numbers $(\mathrm{F}=$ 10.57 , $\mathrm{p}$-value $<0.001)$, and interaction $(\mathrm{F}=19.55$, $\mathrm{p}$-value $<0.001)$. The celebrity effect is confirmed. Interestingly, the non-celebrity subgroup shows higher sustain rate $(0.84)$. As to host place, the results indicate significant effects on flow $(\mathrm{F}=4.87$, $\mathrm{p}$-value $<0.05)$, view $(\mathrm{F}=56.50$, $\mathrm{p}$-value $<0.001)$, numbers $(\mathrm{F}=15.45, \mathrm{p}$-value $<0.001)$, and interaction $(\mathrm{F}=$ $6.31, \mathrm{p}$-value $<0.05$ ). Table 2 provides the details of each subgroup mean and ANOVA results.

To test the structure relationships, we used SmartPLS Version 2.0 M3 in our analysis. In this study, we utilize single indicator to represent certain viewing behavior. Therefore, in measurement model, the correlations among five viewing behavior indicators were examining. Flow and interaction had shown strong relationship with the 0.70 correlation. Table 3 present the correlation among the indicators.

Results of model testing indicated that flow, view, and numbers accounted for 41 percent of variance in sustain. Sustain and numbers can jointly contribute to 45 percent of variance in interaction. The bootstrap resampling procedure was conducted to examine the statistical significance of relationships. Our results show that flow has significant influence on view $(\alpha=$ 0.33 , p-value $<0.001)$, sustain $(\alpha=-0.52$, p-value $<$ $0.001)$, and numbers $(\alpha=0.56, p$-value $<0.001)$. As to sustain, view $(\alpha=-0.32$, p-value $<0.001)$ and numbers $(\alpha=0.79$, p-value $<0.001)$ reveal significant influence. For interaction, sustain $(\alpha=-$ 0.39 , p-value $<0.001)$ and numbers $(\alpha=0.60$, pvalue $<0.001$ ) have significant impacts. Figure 4 presents the results of structural model.

In this stage, the statistical findings provide the HC company many insights for further improvement. For instance, since the project-related live streams reveal higher interaction (mean $=732.92)$ and sustain $($ mean $=0.82)$. The managerial team are keep planning cross-brand cooperative projects. In addition, the interesting finding shows that short length stream reveals higher viewing numbers and sustain than middle one. It inspires the management team to cost and effect thinking when conducting program planning. This project delivered its goals on two dimensions. First, the project team was able to develop the effectiveness evaluation that satisfied HC's requirements. Second, the action taking in this project change the way of $\mathrm{HC}$ to prepare the live streaming program. 
Table 2. ANOVA test results

\begin{tabular}{llllll}
\hline & Flow & View & Numbers & Interaction & Sustain \\
\hline Food & 26701.23 & 17.15 & 366.37 & 462.21 & 0.81 \\
Clothing & 28751.60 & 24.13 & 435.07 & 526.67 & 0.86 \\
Household & 32292.22 & 19.39 & 392.00 & 719.17 & 0.78 \\
Project & 30100.08 & 17.23 & 434.08 & 732.92 & 0.82 \\
\hline F & 1.63 & 2.72 & 1.17 & 2.59 & 0.92 \\
p-value & 0.18 & $0.05^{*}$ & 0.32 & $0.06^{\dagger}$ & 0.44 \\
\hline Long & 34015.94 & 24.78 & 465.06 & 824.76 & 0.81 \\
Middle & 24717.39 & 15.37 & 335.65 & 390.89 & 0.80 \\
Short & 23857.14 & 10.52 & 342.29 & 285.24 & 0.85 \\
\hline F & 13.43 & 35.96 & 10.57 & 19.55 & 0.97 \\
p-value & $0.00^{* * *}$ & $0.00^{* * *}$ & $0.00^{* * *}$ & $0.00^{* * *}$ & 0.38 \\
\hline Celebrity & 31721.30 & 20.53 & 416.74 & 701.34 & 0.79 \\
Non & 23968.91 & 15.50 & 351.74 & 351.98 & 0.84 \\
\hline F & 17.40 & 10.35 & 5.12 & 20.17 & 4.64 \\
p-value & $0.00^{* * *}$ & $0.00^{* * *}$ & $0.03^{*}$ & $0.00^{* * *}$ & $0.03^{*}$ \\
\hline Indoor & 27400.85 & 16.34 & 366.83 & 504.39 & 0.81 \\
Outdoor & 33862.06 & 31.63 & 530.50 & 813.56 & 0.83 \\
\hline F & 4.87 & 56.50 & 15.45 & 6.31 & 0.16 \\
p-value & $0.03^{*}$ & $0.00^{* * *}$ & $0.00^{* * *}$ & $0.01^{*}$ & 0.69 \\
\hline Note: ${ }^{* * * *} \mathrm{p}<0.001{ }^{* *} \mathrm{p}<0.01,^{*}{ }^{*} \mathrm{p}<0.05,^{\dagger} \mathrm{p}<0.10$ & & & \\
\hline
\end{tabular}

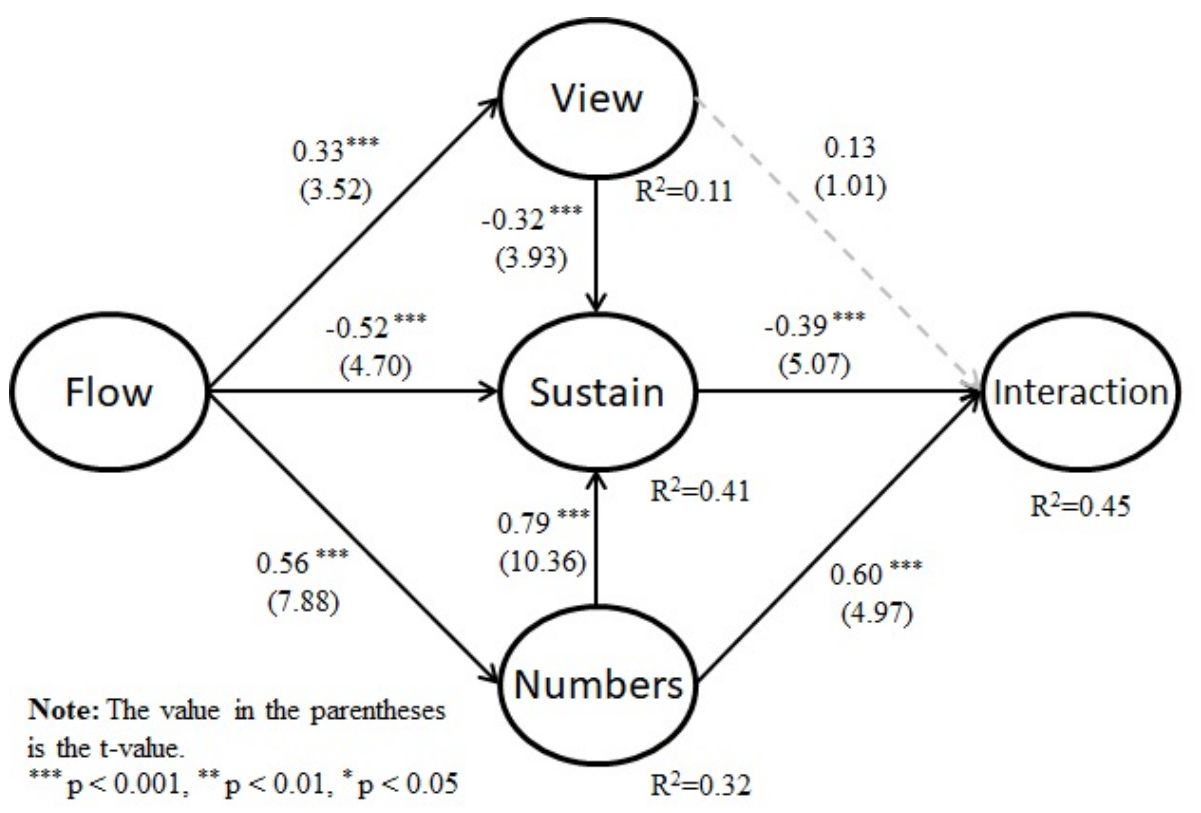

Figure 4. Viewing Behavior Relationships Results 
Table 3. Correlation table

\begin{tabular}{|l|c|c|c|c|c|}
\hline & Flow & View & Numbers & Interaction & Sustain \\
\hline Flow & 1.00 & & & & \\
\hline View & 0.33 & 1.00 & & & \\
\hline Numbers & 0.56 & 0.46 & 1.00 & & \\
\hline Interaction & 0.70 & 0.46 & 0.53 & 1.00 & \\
\hline Sustain & -0.18 & -0.13 & 0.35 & -0.19 & 1.00 \\
\hline
\end{tabular}

\section{Discussion and Conclusion}

This study try to unlock the black box of the live streaming broadcasting effectiveness, especially under the e-Commerce circumstance. In order to address this research problem, researchers conducted a participatory action research through initiating an assessment proposal to a live streaming e-Commerce firm. Using AISAS model as theoretical foundation, research team developed a research framework with suggested actions. Through collecting 30 days of 128 live streams data, authors conducted several statistical analyses. The findings can provide suggestions for further live streaming program design and improvement.

The production of live streaming program should take viewer experience into consideration. According to the results, the AISAS model enable researches to explain the behavior formation in live streaming ecommerce. Managers often consider live streaming as a cost effective way for product promotion. However, live streaming is a show for viewers. Different user experience design will result in different feedback for viewer.

During the attention and interest phase, our findings confirm the arguments of $\mathrm{Du}$ and Wagner (2006). The content (i.e., topic and film length) and social value (i.e., celebrity and place) would have significant impacts on further viewing behavior. In this study, the live streaming about clothing receive more viewing time and viewers. The project-based live streaming will have more interaction volume the others. As to host place, outdoor live streaming contributes to viewing behavior, except the sustain rate. During action taking in the stage two of this study, Aaron found that outdoor can satisfy the curiosity of viewers and show high average view time $($ mean $=31.63)$ than overall average $($ mean $=$ 18.25). The findings also confirm the relationships among viewing behavior indicators.

Based on these findings, research team provides suggestions for the company. First, the program design should be issue leading. To increase the attention and interest of viewers, it is helpful for host to set target issue before live streaming. Different broadcast topic will lead to different viewing results.
When marketers or managers plan live streaming, the issue should be taken into consideration. Second, the celebrity effect can leverage to draw viewers' interest. We will discuss the implication of this finding. Third, the value of behavioral indicator can provide management team as assessment tool for the following performance evaluation.

\subsection{Implications}

To our best knowledge, this work is the first research that utilized action research to collect and analyze real live stream performance data. Instead of perceptual investigation, real data analysis create more value for better understanding the live streaming practice.

The findings provide a structure thinking for live streaming program design. Following the AISAS model, we decomposed the live streaming program into four features, which are topic, film length, celebrity, and place. As our ANOVA test results, firm managers and marketers can benefits by utilizing the structural design thinking to increase the attention and interest of the viewers. It is noteworthy the design of live stream length paradox. As the results, the live streaming broadcasts more than 60 minutes reveal bigger effects on viewing behavior. It also increase the production costs. By comparing the sustain rate, short streams can retain more viewers than the others. This means that there still room for program design improvement.

The celebrity effect is confirmed by our findings. In general, people may think celebrities can bring their offline impacts to online. The results found that celebrities could create bigger flow, longer viewing time, higher viewers at the same time, even twice volume of interaction. It is noteworthy that the sustain rate of celebrity is significant lower than noncelebrity. One possible reason is that non-celebrity can provide more product-related information for viewers. Aaron also mentioned that celebrity can benefit from his or her reputation, but it would not last long. In addition, celebrity also needed to have sufficient knowledge and experience to host the live streaming. 
The lurker effect in viewing behavior. The structures model results show the negative relationship between sustain and interaction. As to our knowledge, we argue this situation could be lurker effect. In Web 2.0, people intend to receive information than give feedbacks. Viewers will be attracted to see the live streaming rather than participate in interaction. The highest interaction can reach the amount of 3,166 . We found that it is possible related to the topic and hosting style. Our research provides managers a set of indicators for measuring the effectiveness.

\subsection{Limitations and Future Research Directions}

The findings of this study should be interpreted according to some limitations. First, as action research is essentially a problem-solving approach, there is the possibility that the difference caused by the research environment. Future research can either conduct survey or incorporate multiple research targets to increase the generalization of findings. Second, according to our investigation, the main viewers of $\mathrm{HC}$ live streaming are female and around 35 to 44 years old. The findings may be biased due to the characteristic of the focal firm. Third, in this study, the reported data and conclusions are based on the working relationship with $\mathrm{HC}$ managers. The study would be limited by our biases and actions. The Hawthorn effect may exist. However, we combine qualitative and quantitative methods as we conducting action research. The real data also collected to ease possible biases. Future research can extend our model by considering other possible determinants and compare possible consumer behavior.

\section{References}

[1] Abdurrahim, M. S., Mukhamad, N., and Setiadi, D. 2019. "Development of AISAS Model to See the Effect of Tourism Destination in Social Media," Journal of Applied Management (17:1), pp 133-143.

[2] Baskerville, R. 2001. "Conducting Action Research: High Risk and High Reward in Theory and Practice," in Qualitative Research in IS: Issues and Trends, E. M. Trauth (eds.), Hershery, PA: Idea Group Publishing.

[3] Bründl, S., Matt, C., and Hess, T. 2017. "Consumer Use of Social Live Streaming Services: The Influence of Co-Experience and Effectance on Enjoyment," in Proceedings of the 25th European Conference on Information Systems.

[4] Cheah, J. H., Ting, H., Cham, T. H., and Memon, M. A. 2019. "The Effect of Selfie Promotion and Celebrity Endorsed Advertisement on Decision-
Making Process: A Model Comparison," Internet Research (29:3), pp. 552-577.

[5] Cole, R., Purao, S., Rossi, M., and Sein, M. 2005. "Being Proactive: Where Action Research Meets Design Research," in Proceedings International Conference on Information Systems 2005.

[6] Colliander, J., and Dahlén, M. 2011. "Following the Fashionable Friend: The Power of Social Media, Weighing Publicity Effectiveness of Blogs Versus Online Magazines," Journal of Advertising Research (51:1), pp. 313-320.

[7] Du, H. S., and Wagner, C. 2006. "Weblog Success: Exploring the Role of Technology," International Journal of Human-Computer Studies (64:9), pp. 789798.

[8] Econsultancy. 2019. "The State of Social Commerce in Southeast Asia," https://econsultancy.com/reports/the-state-of-socialcommerce-in-southeast-asia/ (visited on 1/30/2020).

[9] Hall, S. R. 1924. Retail Advertising and Selling, McGraw-Hill.

[10] $\mathrm{Hu}, \mathrm{Z}$., and Qiao, J. 2017. "Research on We Chat Matrix Marketing Process of E-Commerce Enterprises Based on AISAS Model," in Proceedings of the 2017 International Conference on Arts and Design, Education and Social Sciences.

[11] Iversen, J. H., Mathiassen, L., and Nielsen, P. A. 2004. "Managing Risk in Software Process Improvement: An Action Research Approach,” MIS Quarterly (28:3), pp. 395-433.

[12] Kowalczyk, C. M., and Pounders, K. R. 2016. "Transforming Celebrities through Social Media: the Role of Authenticity and Emotional Attachment," Journal of Product \& Brand Management (25:4), pp. 345-356.

[13] Li, R. 2018. "The Secret of Internet Celebrities: A Qualitative Study of Online Opinion Leaders on Weibo," in Proceedings of the 51st Hawaii International Conference on System Sciences.

[14] Lu, Z., Xia, H., Heo, S., and Wigdor, D. 2018. "You Watch, You Give, and You Engage: a Study of Live Streaming Practices in China," in Proceedings of the 2018 CHI Conference on Human Factors in Computing Systems.

[15] MarketResearch. 2018. "Global B2C Live Streaming Video Platform Market Size, Status and Forecast," https://www.marketresearch.com/QYResearchGroup-v3531/Global-B2C-Live-Streaming-Video12658768 / (visited on 1/30/2020).

[16] Marwick, A. E. 2010. Status Update: Celebrity, Publicity, and Self-Branding in Web 2.0 (Doctoral Dissertation, New York University).

[17] Street, C. T., and Meister, D. B. 2004. "Small Business Growth and Internal Transparency: The Role of Information Systems," MIS Quarterly (28:3), pp. 473-506.

[18] Sugiyama, K., Andree, T., and The Dentsu Cross Switch Team. 2010. The Dentsu Way. New York: McGraw-Hill.

[19] Tang, J. C., Venolia, G., and Inkpen, K. M. 2016. "Meerkat and Periscope: I Stream, You Stream, Apps 
Stream for Live Streams," in Proceedings of the 2016 CHI Conference on Human Factors in Computing System.

[20] Todd, P. R., and Melancon, J. 2017. "Gender and Live-Streaming: Source Credibility and Motivation," Journal of Research in Interactive Marketing (12:1), pp. 79-93

[21] Wei, P.S., and Lu, H.P. 2013. "An Examination of the Celebrity Endorsements and Online Customers Reviews Influence Female Consumers' Shopping Behavior," Computers in Human Behavior (29:1), pp. 193-201.

[22] Zhang, Q. 2019. "A Research Based on AISAS Model of College Students Information Contact Investigation of Chinese Dream," Journal of Physics: Conference Series (1168:3). 